\title{
OS PAÍSES LUSÓFONOS E O DESAFIO DE UMA CIRCUM-NAVEGAÇÃO TECNOLÓGICA
}

\author{
Moisés de Lemos Martins
}

\begin{abstract}
Resumo
Proponho neste artigo a hipótese de estarmos a fazer uma travessia tecnológica, em muitos aspetos análoga à travessia marítima europeia dos séculos XV e XVI (Martins, 2015a, $2017,2018 \mathrm{a}, 2018 \mathrm{~b})$. Coloco, pois, em confronto a natureza tecnológica da atual globalização financeira e a natureza comercial da expansão marítima europeia. E se da primeira travessia resultou a colonização de povos e nações, com a segunda travessia passámos, em século e meio, àquilo a que Edgar Morin chamou a "colonização do espírito" de toda a comunidade humana (Morin, 1962). Neste contexto, tomei em consideração as consequências, para a cultura, da aceleração da época pela tecnociência, que tem mobilizado o humano, "total" (Jünger, 1930) e "infinitamente" (Sloterdijk, 2010), para as urgências do presente (Martins, 2010). Por outro lado, vou situar nos estudos pós-coloniais as identidades transnacionais e transculturais, analisando as comunidades lusófonas no contexto da "batalha das línguas", para utilizar uma expressão do linguista moçambicano, Armando Jorge Lopes (2004). Por essa razão, vou considerar a "circum-navegação tecnológica" (Martins, 2015a, 2017, 2018a, 2018b), a empreender por todos os países do espaço lusófono, como um combate pela ordenação simbólica do mundo (Bourdieu, 1977, 1979, 1982), onde se colocam os problemas de língua hegemónica e de subordinação política, científica, cultural e artística (Martins, 2015b). Trata-se, pois, de uma travessia eletrónica, utilizando sites, portais, redes sociais, repositórios e arquivos digitais, e ainda, museus virtuais. E o ponto de vista adotado é o de que uma grande língua de culturas e de pensamento, como é a língua portuguesa, não pode deixar de ser, igualmente, uma grande língua de conhecimento, humano e científico.
\end{abstract}

\section{Portuguese-SPEAKing Countries AND The Challenge OF A TECHNOLOGICAL CIRCUMNAVIGATION}

\begin{abstract}
In this article, I propose the assumption that we are making a technological journey, analogous in many respects to European ocean voyages of the $15^{\text {th }}$ and $16^{\text {th }}$ centuries (Martins, 2015a, $2017,2018 \mathrm{a}, 2018 \mathrm{~b}$ ). Thus, I confront the technological nature of the current financial globalization and the commercial nature of European maritime expansion. Whereas the first journey resulted in the colonization of peoples and nations, in the second journey we moved, in a century and a half, to that which Edgar Morin called the "colonization of the spirit" of the entire human community (Morin, 1962). Within this context, I took into consideration the consequences, for culture, of the acceleration of the time via technology, which has mobilized human beings, "totally" (Jünger, 1930) and "infinitely" (Sloterdijk, 2010), in view of the urgencies of the present (Martins, 2010). On the other hand, I will use post-colonial studies to situate transnational and transcultural identities, by examining Portuguese-speaking communities within the context of
\end{abstract}


the "battle of languages," to use an expression coined by Mozambican linguist Armando Jorge Lopes (2004). This is why I will consider "technological circumnavigation" (Martins, 2015a, 2017, 2018a, 2018b), to be undertaken by every Portuguese-speaking country, like a fight for the world's symbolic ordering (Bourdieu, 1977, 1979, 1982), where we raise hegemony language-related problems and those pertaining to political, scientific, cultural and artistic subordination (Martins, $2015 \mathrm{~b}$ ). This is, therefore an electronic journey, using sites, portals, social media, digital repositories and archives, as well as virtual museums. What's more, the viewpoint adopted is that which states a great language of cultures and thinking, such as Portuguese, likewise cannot avoid being a great language of human and scientific knowledge.

\section{KEYWORDS}

Post-colonialism; Lusophony; Portuguese language; transcultural and transnational identities; technological circumnavigation

\section{Polí́tica dA LÍNgUA E LUSOFONIA ${ }^{1}$}

Logo na abertura do estudo, "Can the subaltern speak", Gayatri Spivak confronta os autores, que no Ocidente identificamos como os "pensadores da diferença" (sobretudo, Marx, Althusser, Derrida, Foucault, Deleuze, Guatarri e Lyotard), com uma questão fundamental. Nestes autores é ainda a razão ocidental que se exprime, e não a razão daquele que identificamos como "o outro". O poder do outro (Marx e Foucault), o desejo do outro (Deleuze e Guatarri) e o interesse do outro (Marx e Althusser) não têm na "filosofia da diferença" (Derrida e Lyotard) a voz do "outro". E por essa razão, "o outro" não é "sujeito"; é apenas a alienação de um sujeito, pois não passa de uma projeção do sujeito ocidental, com as suas categorias e contexto. Em consequência, Gayatri Spivak procede a uma crítica cerrada da "problematização do sujeito", feita por estes emblemáticos pensadores. E ao fazê-lo, coloca em questão a representação do sujeito do Terceiro Mundo, projetada pelo discurso ocidental. Como sabemos, o centro nunca deixou de projetar e conceptualizar aquilo que considera como as suas periferias, a África, o Oriente, a América Latina, enfim o Terceiro Mundo. Gayatri Spivak (1988/1994, p. 66) conclui, então, que a crítica radical, que observamos nestes autores ocidentais, não é tão radical assim, pois manifesta "um desejo interessado em conservar o sujeito ocidental, ou o Ocidente como Sujeito".

Tomando como objeto a lusofonia, interrogo neste artigo a condição política, estratégica e cultural dos países lusófonos, no contexto da globalização, que é sobretudo uma realidade financeira e tecnológica, com uma língua hegemónica, o inglês, e que, por esta razão, coloca todos estes países perante o problema da sua subalternidade linguística, cultural, política e científica. Ou seja, a comum condição de subalternidade política dos países lusófonos exprime-se pela comum condição de subalternidade da sua língua, culturas e conhecimento. Mas embora possamos projetar para os países lusófonos um

\footnotetext{
' Investigação desenvolvida no contexto do projeto "Memories, cultures and identities: how the past weights on the present-day intercultural relations in Mozambique and Portugal?", financiado pela Rede Aga Khan para o Desenvolvimento e pela Fundação para a Ciência e Tecnologia.
} 
sonho de convergência de culturas, artes e conhecimento, o espaço lusófono, na sua multiplicidade e diversidade, territorial, cultural, artística, não deixa de ser um espaço policentrado, hierarquizado, assimétrico e largamente desconhecido, para os cidadãos dos próprios países que o compõem.

São tecnológicas as condições da época. É essa a razão que me leva a encarar o ciberespaço como um novo lugar do conhecimento científico, sem dúvida em língua inglesa, com as políticas de comunicação a saltar para os websites, os portais eletrónicos, as redes sociais, os repositórios digitais e os museus virtuais. Mas do ponto de vista em que me coloco, o novo lugar do conhecimento científico é em língua portuguesa.

A ideia de lusofonia inscreve-se, pois, no contexto do atual debate sobre a globalização do conhecimento e da cultura digital. E para todos os povos, a globalização apresenta-se, hoje, como um destino inexorável, de mobilização para um mercado global (Martins, 1998), sendo, em certa medida, única e definitiva a identidade dos indivíduos de todas as nações, doravante móveis e flexíveis (sem direitos sociais), mobilizáveis (respondendo às necessidades do mercado), competitivos (adotando a lógica da produção) e performantes (realizadores de sucesso) (Martins, 2015b, pp. 9-10).

Nestas circunstâncias, o espaço transcultural e transnacional dos povos que falam Português não pode deixar de se confrontar com um desafio estratégico: encontrando-se, hoje, do mesmo lado da barricada, de países dominados, subalternos, e em permanência empurrados para a periferia da globalização hegemónica, um espaço falado numa única língua, o Inglês, a lusofonia pode ser encarada como uma circum-navegação tecnológica e intercultural, uma travessia, a ser realizada por todos os povos lusófonos, no sentido do interconhecimento, da cooperação, cultural, científica, social, política e económica, e também de afirmação da diversidade no mundo, enfim, uma circum-navegação que abra os confins do desenvolvimento humano.

A circum-navegação assinala, classicamente, a experiência da travessia de oceanos e a ultrapassagem do limite estabelecido, de mares, terras e conhecimentos. A circum-navegação constitui, pois, uma boa metáfora para caracterizar a (a)ventura lusófona, não apenas da cultura da diversidade e da comunicação intercultural, mas também da ciência produzida em português. A circum-navegação tecnológica a empreender far-se-á, então, através de sites, portais, redes sociais, repositórios e arquivos digitais, assim como de museus virtuais.

Sem dúvida que a ideia de lusofonia não é consensual em Portugal, nem no espaço alargado dos países de língua portuguesa. Antes de mais nada, é preciso ter presente a identidade multicultural e heterogénea, que constitui cada comunidade do espaço lusófono, assim como a relação intrincada e ambivalente que os mundos não ocidentais têm com os antigos países colonizadores². E do mesmo modo, é preciso considerar os média de cada um dos países do espaço lusófono, no contexto das suas estratégias identitárias, sejam elas locais, nacionais ou transnacionais.

Para sintetizar os argumentos que têm sido apresentados contra a ideia de lusofonia, convoco Miguel Tamen, Professor de Literatura, da Universidade Lisboa. Em

${ }^{2}$ Sobre a identidade multicultural e heterogénea do espaço lusófono, veja-se, por exemplo, o estudo que realizei com Regina Brito sobre Moçambique e Timor-Leste (Brito \& Martins, 2004). 
vários artigos de imprensa e entrevistas ${ }^{3}$, Miguel Tamen increpa a lusofonia, por não entender que as pessoas e os países possam estar unidos por uma mesma língua. Em seu entender, é uma quimera imaginar a língua como um património. E não sendo um património, não existiria razão para a defender. Mas, sobretudo, a lusofonia é para Miguel Tamen (2012) uma noção errada, por corresponder, em Portugal, a "uma espécie de colonialismo de esquerda". Depois de ter desaparecido o império colonial português, a lusofonia não passaria de um seu substituto espiritual. Substituiria, hoje, as antigas palavras de "fé, império e religião" (Tamen, 2012). Em suma, a lusofonia decorreria da miragem de um excecionalismo português - esse excecionalismo, que imaginou a colonização portuguesa como um caso único na história da colonização europeia, imagina hoje os portugueses como um povo diferente de todos os outros (Tamen, 2012) ${ }^{4}$.

Este ponto de vista é também partilhado no Brasil, por vários autores, entre os quais, Carlos Alberto Faraco $(2012,2016)$. Em síntese, Faraco entende que o projeto da lusofonia é uma "quimera", sobretudo porque o seu discurso é o da exaltação de valores abstratos, como a "comunhão dos povos" e a "harmonia das culturas" (Faraco, 2012).

Entretanto, no artigo que publicou no jornal Observador, Miguel Tamen (2016) defende um ponto de vista desconcertante sobre política da língua. Entende que devem desaparecer todas as cátedras portuguesas, pagas pelo governo português em universidades estrangeiras; todos os professores de português, pagos pelo governo português, fora de Portugal; todas as regras sobre ortografia, e todas as tentativas, a seu ver grotescas, de sugerir que por escreverem da mesma maneira, as pessoas vão falar da mesma maneira. Concluindo o seu ponto de vista, Miguel Tamen proclama: acabe-se com o Instituto Camões, porque "a melhor política da língua e a única decente é: nenhuma" (Tamen, 2016).

Os assuntos relativos à língua portuguesa e à lusofonia são importantes, a meu ver, pelo facto de a invocação de uma língua e de um espaço transcultural e transnacional comuns constituírem, sobretudo do ponto de vista estratégico, questões relevantes, tanto para Portugal, como para todos os países de língua portuguesa, assim como para as suas diásporas.

Em todos os tempos, as comunidades humanas viram-se confrontadas com duas questões fundamentais, com o problema da ordem, na tentativa de dar resposta à exigência de viver em comunidade; e também, com o problema da história, indagando sobre as possibilidades da ação humana. Nestes aspetos, a nossa época não é distinta de todas as outras. E o debate sobre a língua portuguesa e, por via dela, sobre a constituição de uma comunidade lusófona, considero-os modos de dar resposta, tanto à exigência de viver em comunidade, como às possibilidades da ação humana.

\footnotetext{
3 Veja-se, por exemplo, as entrevistas dadas, por um lado, ao jornal $i$ (24 de abril de 2012); por outro lado, à revista Ler (n. 149, primavera de 2018, pp. 20-33). Veja-se, ainda, o artigo de opinião publicado no jornal Observador (8 de janeiro de 2016).

${ }^{4}$ A ideia de "colonização doce", que teria caracterizado o processo da expansão marítima portuguesa, teve no salazarismo e no luso-tropicalismo os seus principais apoios ideológicos (Castelo, 1998). E por muito que Vamireh Chacon (2000, 2002) remeta para o desconhecimento do pensamento de Gilberto Freyre a hostilidade que muitos investigadores afivelam ao luso-tropicalismo, a sua mera convocação é suficiente anátema para muitos autores, que nele denunciam um juízo condescendente no que respeita à violência histórica em que consistiu o colonialismo (por exemplo: Alexandre, 1973; Bastide, 1972; Boxer, 1963).
} 
É certo que a construção, na diversidade, da grande comunidade de culturas, que o espaço lusófono constitui, exige o exercício de um olhar reflexivo sobre os modos como ocorre a interação entre os povos deste espaço, e também sobre os modos como se realiza a interação entre os cidadãos dos vários países lusófonos, porque se trata, em todos os casos, de territórios marcados pela heterogeneidade e pela diferença. Ao falarmos, todavia, do espaço lusófono, estamos a falar de comunidades que, oficialmente, se exprimem em língua portuguesa, uma língua que por ser de culturas, pensamento e conhecimento, também concorre para a construção de comunidades lusófonas, sejam elas culturais, artísticas ou científicas.

É hoje central na comunidade académica o debate sobre as políticas científicas e sobre os modos de contrariar o modelo hegemónico de fazer ciência, um modelo que apaga a diferença, tanto pela língua de uso, o Inglês, como pelo paradigma científico que impõe, o anglo-saxónico 5 . Trata-se, sem dúvida, de uma questão estratégica. Uma língua que não se esforce para dizer os avanços do seu tempo, e também as suas contradições e inquietações, uma língua que não se esforce para dizer os bloqueios e os impasses da sua época, quero dizer, uma língua que não tenha pensamento, é uma língua que não cria conhecimento. E se o não fizer, se não criar conhecimento, é uma língua arcaica, que estiola e acaba por morrer ${ }^{6}$.

Realizar esta tarefa, de fazer ciência em língua portuguesa, em todos os países que a falam, e também nas suas diásporas, é estar a dar oportunidades ao conhecimento, que se exprime na diversidade das culturas faladas em Português, assim concorrendo para a construção de uma comunidade científica lusófona, policentrada e polifacetada, uma comunidade com sentido humano, que é sempre uma comunidade com o sentido do debate e da cooperação, no respeito pela diversidade e pela diferença entre as culturas.

\section{A NOVA CIRCUM-NAVEGAÇÃo TECNOLÓGICA ${ }^{7}$}

A nova circum-navegação tecnológica, em língua portuguesa, tem um desiderato cooperativo, transnacional e transcultural, um desiderato em termos científicos, pedagógicos, culturais e artísticos. Espera-se de uma tal circum-navegação que possa desenvolver literacias, que promovam a cultura da diversidade e da comunicação intercultural, nos países e regiões de língua portuguesa, assim como das suas diásporas. Aliás, foi este o sentido que foi dado, tanto à criação do Museu Virtual da Lusofonia ${ }^{8}$, na Universidade

\footnotetext{
${ }_{5}^{5}$ Sobre a generalização da língua inglesa como língua de ciência e sobre o paradigma anglo-saxónico de fazer ciência, escrevi o artigo "A liberdade académica e os seus inimigos" (Martins, 2015b).

${ }^{6}$ Este ponto de vista articula-se com os objetivos gerais do trabalho que escrevi sobre a renovação da pesquisa sobre a cultura, que se abre, hoje, às políticas culturais e científicas, e compreende os estudos étnicos, pós-coloniais, comunicacionais, antropológicos, etnográficos e feministas, firmando um compromisso com o atual e o contemporâneo, o que também quer dizer, com o presente e o quotidiano (Martins, 2015d)

7 Esta secção retoma alguns parágrafos, reescrevendo-os, do estudo que realizei sobre "Comunicação da ciência, acesso aberto do conhecimento e repositórios digitais" (Martins, 2017).

${ }^{8}$ Disponível em http://www.museuvirtualdalusofonia.com/
} 
do Minho, em 2017, como à criação da Revista Lusófona de Estudos Culturais ${ }^{9}$, também na Universidade do Minho, em 2013.

Em ambos os casos, pretende-se a constituição de bases de conhecimento, ou seja, de repositórios digitais e de museus virtuais, em Ciências Sociais e Humanas, à escala lusófona, que possam representar, não apenas uma importante afirmação científica em língua portuguesa, mas que reúnam, também, um importante acervo, cultural e artístico, que permita compreender a lógica das interdependências, do ponto de vista da comunicação intercultural. Ou seja, inspirando-nos em Tzvetan Todorov (1982), procurar-se-á com este acervo científico, cultural e artístico, esclarecer os juízos de valor que temos sobre o outro, assim como os estereótipos com que os enquadramos. Tratar-se-á de esclarecer, também, as práticas concretas de assimilação, submissão ou indiferença, relativamente ao outro, assim como de contrariar a "metafísica da unidade", que possa estar presente na ideia de comunicação intercultural, se porventura desconhecer os processos sociais de segregação, dominação e tomada de poder (Martins, 2014).

A circum-navegação é uma boa metáfora para caraterizar a atual experiência tecnológica, dado que nos ajuda a pensar a travessia a fazer naquela que é, afinal, a experiência contemporânea por excelência ${ }^{10}$. As circunstâncias pós-coloniais são as de um mundo mobilizado nas suas práticas por toda a espécie de tecnologias, sobretudo por plataformas móveis de comunicação, informação e lazer (iPad, tablets, smartphones, etc.), por novas formas de interação social (redes sócio-técnicas) e por modelos emergentes de interação (por exemplo, aplicações e videojogos).

Na circum-navegação clássica houve o sextante, o astrolábio, a esfera armilar e a balestilha. Mas havia sobretudo as estrelas, para nos conduzir na noite. Deixámos, entretanto, de olhar para as estrelas e passámos a olhar para os ecrãs, como assinala Paul Virilio (2001, p. 135). Ou seja, da história de sentido em que se inscreviam as estrelas, o Ocidente abriu caminho para os ecrãs, o que quer dizer, para "a inovação, a hibridez e a interatividade" (Martins, 2011/12, p. 49).

Os novos média, ou média digitais, significam isso mesmo: a comunicação mediada por computador, e, em consequência, a inovação, a hibridez e a interatividade. A inovação significa práticas que impõem uma intervenção tecnológica. E porque se trata de práticas tecnológicas, há que discutir nos média digitais, antes de mais nada, a programação e o design (Foster, 2002).

Em concomitância com as práticas tecnológicas, surgem, entretanto, novas práticas de comunicação, que impõem uma alteração do sentido da leitura, assim como uma alteração do sentido do olhar. Hoje, ler o jornal, ver televisão ou ir às exposições de um museu, são exercícios de comunicação, que incluem, todos, práticas de navegação

\footnotetext{
${ }_{9}$ Disponível em http://www.rlec.pt/index.php/rlec

${ }^{10}$ A figura da circum-navegação, associada à ideia de viagem tecnológica, é desenvolvida, originalmente, na tese de doutoramento de Stéphane Hugon, defendida em 2007, na Sorbonne, com o título, Circumnavigations, la construction sociale de l'identité en ligne. Esta tese foi publicada em 2010, mantendo a figura da circum-navegação no título: Circumnavigations. L'Imaginaire du voyage dans l'expérience internet. Colocando-se do ponto de vista de "uma sociologia dos espaços eletrónicos", Hugon interroga, entre outros aspetos, "uma cultura da deambulação", "uma genealogia da deriva”, "o que significa habitar", "o que é uma paisagem" e, ainda, "a dinâmica comunitária".
} 
Web, ou seja, práticas de comunicação, em condições específicas de tempo, espaço e interlocução: downloads, pirateados ou não, visualizações no YouTube, discussões nas redes sociais, expansão de artigos em posts de blogues, expansão de imagens em vídeos no YouTube.

Os média digitais significam, também, a hibridez, o que quer dizer, uma síntese tornada possível pela realidade técnica, que abre espaço para seres artificiais, mundos virtuais e experiências simulacrais. E, neste contexto, uma coisa é, por exemplo, o processo de leitura, caraterizado por Roman Jakobson, em Lingüística e Comunicação (2003), que supõe uma tradução intersemiótica, ou de transmutação, no processo de interpretação dos signos verbais por meio de sistemas de signos não verbais. E coisa bem diferente é a leitura a que se refere o transmedia storytelling, ou cross-media, que significa a expansão da narrativa, por meio de vários média (Sousa, 2018; Sousa, Martins \& Zagalo, 2016) '1".

Os média digitais significam, ainda, a interatividade, e não propriamente a interação, ou seja, significam práticas sociais, que não remetem apenas para a liberdade e autonomia dos atores sociais; remetem, igualmente, para os constrangimentos da ação social, a qual ocorre, sempre, em condições específicas de tempo, espaço e interlocução.

E são os atuais dispositivos eletrónicos de programação e de design, numa linha que é tanto de continuidade como de rompimento com a máquina fotográfica, que generalizam o processo de produção de imagens como práticas de "simulacro e simulação" (Baudrillard, 1981), entre a troca lúdica e a partilha diária de imagens digitais, nos ambientes reais e virtuais dos nossos telemóveis e computadores, de idêntica forma à que ocorreu, no passado, com os postais ilustrados (Correia, 2013; Martins \& Correia, 2014).

Os média digitais significam, então, novas práticas de produção do sentido, ou seja, novas práticas da linguagem e da comunicação: por um lado, textualidades multimodais ou transmediáticas ("hipertextualidades"); e por outro, formas de comunicação digital interativa. Entretanto, nesta travessia, atribuímo-nos uma "pele tecnológica" (Kerckhove, 1997), uma pele para a afeção, o que quer dizer, uma pele para o ser-e-estar-com-outros.

No Ocidente, as estrelas têm, de facto, virtualidades narrativas: sempre nos conduziram nas travessias (de mares, desertos e tentações); tinham sentido, ou melhor, inscreveram-nos numa história de sentido, entre uma génese e um apocalipse. $E$ ao inscreverem-nos nesta história da salvação, sempre nos impediram de naufragar. $\mathrm{Na}$ cultura ocidental, temos até uma estrela por excelência, aquela que surgindo a Oriente conduziu o Ocidente durante 20 séculos. A estrela que conduziu os Reis Magos permitiu, com efeito, a narrativa da Epifania - o mistério de um Deus encarnado, que fundou no Cristianismo a civilização ocidental.

Ao retomar o imaginário das estrelas, a nova circum-navegação, uma circum-navegação eletrónica, concretiza o novo paradigma cibercultural, uma travessia em direção à Nova América de um novo arquivo cultural, que reativa em nós formas antigas, o

\footnotetext{
"Carlos Alberto Scolari (2011, p. 128) utiliza como sinónimos os conceitos de transmedia storytelling e cross-media, o último dos quais, reconhece, é todavia mais usado nos meios profissionais do que nos meios académicos. O termo transmedia storytelling foi cunhado por Henry Jenkins (2003). François Jost (2011, p. 95) prefere falar de "luta intermídia", em vez de utilizar o termo convergência. Ver, também, sobre transmedia storytelling, Christian Salmon (2007), que propõe um ponto de vista crítico sobre a storytelling: "uma máquina de fabricar histórias e de formatar espíritos".
} 
arcaísmo, enfim a mitologia, e ao mesmo tempo reconfigura em permanência a comunidade, pelo desejo de ser-e-estar-com-outros ${ }^{12}$.

\section{A TRAVESSia De ATMOSFeras E PAISAGENS TECNOLÓGiCAS}

A travessia tecnológica dá conta da mutação digital, que hoje ocorre na sociedade contemporânea e faz convergir tecnologias da informação, média, artes e culturas, ao mesmo tempo que altera comportamentos, atitudes e práticas (Jenkins, 2008).

Sendo seu propósito, portanto, realizar a circum-navegação de um território, feito de atmosferas e paisagens tecnológicas, em busca da nova América de um novo arquivo cultural, a travessia tecnológica, a realizar pelos povos lusófonos, articula-se com a exigência da utilização de três tipos de literacias complementares: uma literacia dos média, que nos habilite para a crítica dos conteúdos; uma literacia informativa, que torne possível avaliar documentos e dados online; e ainda, uma literacia computacional, que permita navegar e criar conteúdos online. Espera-se que a combinação destes três tipos de competências mediáticas, na era da técnica, incremente a participação cívica e a ação criativa, tanto online como offline.

A literacia digital precisa, com efeito, de se tornar nuclear na travessia tecnológica a empreender, de modo a poder ser criativa na cultura. A exigência da criatividade na cultura, exige, pois, desta travessia tecnológica, tanto a criação cultural e artística, nas atuais condições tecnológicas, como uma preocupação com a cidadania e a inclusão social (Kittler, 2011). Por essa razão, não podemos deixar de nos confrontar, também, com as políticas de acesso integral a bases de dados digitais, museus virtuais e repositórios de conhecimento em acesso aberto, que hoje enformam as práticas dos agentes culturais. Em síntese, a travessia tecnológica a empreender por todos os países lusófonos não pode deixar de interrogar estes novos contextos de significação. Trata-se não apenas de interrogar o acesso a tecnologias e a ferramentas tecnológicas, como também de interrogar o acesso à participação cívica e à criação cultural e artística, em ambientes tecnológicos.

Sem dúvida, são, hoje, desafios para a travessia tecnológica, as novas atmosferas tecnológicas, que concretizam as práticas dos profissionais do novo contexto digital, particularmente web designers, curadores online, gestores de museus virtuais, ativistas da web, youtubers. E constituem, também, atmosferas tecnológicas, desafiadoras para a travessia a empreender, a proteção e a segurança dos conteúdos culturais digitais, assim como a comunicação desses conteúdos.

Do que se trata, com efeito, nesta nova atmosfera tecnológica é de uma cultura em "status nascendi" (Maffesoli \& Martins, 2011, pp. 41-43), uma cultura que tanto compreende novas ferramentas, de artistas e criadores, como perpassa arquivos, museus, gravações-vídeo e filmes. Em síntese, esta cultura em status nascendi é uma cultura feita de paisagens tecnológicas.

${ }^{12}$ Desenvolvi a ideia de cibercultura como circum-navegação tecnológica, noutros textos. Ver, neste sentido: Martins, 2011a, pp. 18-19, 2011/2012, pp. 52-54, 2015a, pp. 37-43, 2015/2016, pp. 13-14, 2017, pp. 21-26; Maffesoli \& Martins, 2011, pp. 43-44. 
Podemos, igualmente, assinalar, entre outras questões centrais desta circum-navegação cibercultural, a formação de novos públicos para as culturas e as artes, assim como as políticas específicas para os repositórios digitais, que têm em vista, sempre, o acesso aberto ao conhecimento.

E não podemos esquecer, neste contexto de circum-navegação tecnológica, os ambientes patrimoniais em rede, cujos acervos são em fluxo. Quer isto dizer, por exemplo, que peças, obras e narrativas, tanto culturais como artísticas, podem ser transferidas de um meio de comunicação para outro (transmedia remix) (Sousa, Zagalo \& Martins, 2012), e mesmo convertidas, mediante licença, em mercadoria, ou até darem origem a um outro produto.

Finalmente, não podemos perder de vista o facto de que a cultura digital precisa de estar ancorada em poderosos territórios físicos e em pesadas infraestruturas tecnológicas. Porque apenas deste modo é possível criar "territórios culturais" que sirvam o desenvolvimento local sustentado' ${ }^{13}$.

\section{A LUSOFONIA COMO FIGURA DA MODERNIDADE}

Uma ideia de lusofonia, que projete o sentido de uma promessa de comunidade, não pode ser alheia à cinética contemporânea, que é uma cinética tecnológica. Não pode, pois, deixar de se inscrever no contexto do debate sobre a globalização, que é, como atrás salientei, uma realidade de cariz eminentemente económico-financeiro, comandada pelas tecnologias da informação. Esta ideia de globalização dá-nos uma identidade definida, ou seja, definitiva, uma identidade de indivíduos móveis, mobilizáveis, competitivos e performantes no mercado global (Martins, 2015b, pp. 9-10). E exprime, além disso, uma conceção cosmopolita de cultura, "a cultura-mundo" (Martins, Cabecinhas \& Macedo, 2011), uma "metafísica da unidade", servida por uma única língua, o inglês (Martins, 2014).

Mas se é verdade que o mundo se unificou, através da expansão do capitalismo financeiro e especulativo, também se diversificou, por via de resistências e adaptações diversas (Sahlins, 1993, p. ix). Como assinala Manuel Ivone Cunha, "a integração global e a diferenciação local seriam até certo ponto concomitantes. A diferenciação desenvolver-se-ia como resposta à integração mundial" (Cunha, 2015, p. 277).

É este o contexto que me parece poder enquadrar a lusofonia, dado situar-se naquilo a que podemos chamar de "globalização multiculturalista". A "globalização cosmopolita", fundada nas tecnologias da informação e na economia, não pode ser contrariada por indivíduos solitários e impotentes, nem por Estados-nações em crise. Pode-o ser, todavia, pela "globalização multiculturalista", que reúne os povos de áreas geoculturais alargadas, promove e respeita as diferenças, dignificando, do mesmo passo, as línguas nacionais. A "globalização multiculturalista" é a globalização do que é diverso, do que é diferente,

\footnotetext{
${ }^{13}$ Foram estes os princípios que deram forma à criação do Museu Virtual da Lusofonia, disponível em www.museuvirtualdalusofonia.com. Sobre a natureza, os objetivos e a estrutura do Museu Virtual da Lusofonia, veja-se Martins, 2017, pp. 46-49.
} 
do que é outro. É feita pela mistura, pela miscigenação de etnias, línguas, memórias e tradições (Martins, 2011b) ${ }^{14}$. E é este o sentido que nos parece dever servir a lusofonia.

Quanto à figura da "portugalidade", uma assombração que vampiriza a figura da lusofonia (Sousa, 2017), devemos alinhá-la ao lado de todas as outras figuras, antigas e modernas, que a vampirizam, sejam figuras luso-tropicalistas ou neocoloniais, sejam figuras de ressentimento, portuguesas, brasileiras, moçambicanas ou angolanas, ou de outros países lusófonos ${ }^{15}$.

Este artigo ensaia, com efeito, sobre as possibilidades da lusofonia, não como o imaginário de um país, mas como um espaço linguístico e geocultural, transcultural e transnacional. Queremos dar à lusofonia o sentido de um imaginário inextricavelmente português, brasileiro, angolano, moçambicano, guineense, cabo-verdiano, são-tomense, timorense, galego, assim como de todas as diásporas destes povos. Como assinala José Luiz Fiorin (2006, p. 46),

é necessário que não haja autoridade paterna dos padrões lusitanos. (...)

A lusofonia não será pátria, porque não será um espaço de poder ou de autoridade. Será mátria e será frátria, porque deve ser o espaço dos iguais, dos que têm a mesma origem. Se assim não for, ela não terá nenhum significado simbólico real, será um espaço do discurso vazio de um jargão político sem sentido.

Ou seja, o espaço cultural da lusofonia e a comunidade e a confraternidade de sentido e de partilha comuns só podem realizar-se pela assunção da pluralidade e da diferença e pelo conhecimento aprofundado de uns e de outros.

À pergunta "podem os subalternos falar?", em tempos endereçada por Gayatri Spivak (1988) contra a razão ocidental, podemos, pois, responder com uma ideia de lusofonia, que é um combate, não apenas pela afirmação da diferença plural, em que radica o espaço lusófono, mas também pelo reconhecimento da diversidade dos povos e culturas que o constituem.

Como temos procurado demonstrar, este entendimento da lusofonia nada tem a ver com "uma nostalgia de império". Assim como também nada tem a ver com qualquer justificação histórica do projeto colonial que, no passado, mobilizou as nações europeias. A ideia de lusofonia não ignora, pois, o logocentrismo - um discurso único, que foi também o único sentido; o etnocentrismo - uma narrativa única, entre génese e apocalipse, que continha a memória de um povo, uno e único; o imperialismo, que serviu a razão de um único Estado; enfim, o colonialismo, que alimentou o tráfico de escravos e impôs a dominação dos povos do sul pelos povos do norte.

\footnotetext{
${ }^{14}$ Sobre a tensão entre a globalização cosmopolita e a globalização multiculturalista, ver "Globalization and lusophone world. Implications for citizenship" (Martins, 2011b).

15 Sobre os equívocos que parasitam a figura da lusofonia, ver, por exemplo, Martins, 2014, pp. 25-27.
} 


\section{As Cî̂nCIAS da CoMUNiCAÇÃo F O ESPAÇO TRANSCULTURAL E TRANSNACIONAL LUSÓfono}

É da natureza das Ciências da Comunicação ocuparem-se dos processos de significação social. Enquadra-se neste contexto o estudo das narrativas, que classicamente interrogou as suas funções (Propp e Jakobson), a sua lógica (Barthes, Greimas, Peirce), e os modos como nela se produz sentido (Bakhtin, Halliday, Metz, Baudrillard, Bourdieu). Entretanto, ao ocuparem-se dos média digitais, as Ciências da Comunicação interrogam as narrativas visuais tecnológicas (Lev Manovich, Henry Jenkins, Kress, van Leeuwen, Jay Bolter, Richard Grusin, Steven Shaviro, Carlos Scolari).

E é das narrativas visuais tecnológicas que nos ocupamos neste estudo. Porque são elas que constituem o contemporâneo (Martins, 2007). Ao interrogarem a nossa atual experiência, as Ciências da Comunicação dão-nos a ver paisagens tecnológicas, que exprimem atmosferas sensíveis e sociais, e que remetem, tanto para um tempo de mobilização total para o mercado (Martins, 2010), como simultaneamente remetem para um tempo agitado, um tempo de sobreaquecimento contínuo. As narrativas visuais tecnológicas mobilizam, pois, as emoções e configuram formas melancólicas, que resultam da combinação entre techne e aesthesis, ou seja, entre técnica e emoção, e também, entre techne e arche, o que quer dizer, entre o novo e o arcaico (Martins, 2003, 2005, 2007, 2009; Martins, Oliveira \& Correia, 2011).

Ora, estando os países lusófonos convocados a empreender esta viagem tecnológica, como quem abre "a última porta para a noite" (Steiner, 1992, p. 6) ${ }^{16}$, pela dificuldade da travessia a realizar, relembro a conferência de Heidegger (1988, p. 38), pronunciada em 1953, sobre "A questão da técnica" (Die Frage nach der Technik). Embora o filósofo alemão considere a técnica como o perigo, argumenta com o verso de Hölderlin, mas "Lá onde está o perigo cresce também o que salva".

É este o mote que utilizo para a proposta que faço para o espaço lusófono. A circum-navegação tecnológica, a que a contemporaneidade nos convoca, dá conta do acontecimento maior da experiência contemporânea, o da fusão de techne e bios. E nós podemos encarar esta experiência como condição de possibilidade para uma circum-navegação lusófona, ou seja, como condição de possibilidade para uma travessia a realizar pelos povos lusófonos, em redes transculturais e transnacionais de conhecimento, que reconfigurem em permanência o sentido de comunidade, enfim, desejo de ser-e-estar-com-outros.

\section{REFERÊNCIAS}

Alexandre, V. (1973). Le colonialisme portugais: réalité et mythe. In Suisse-Portugal, de l'Europe à l'Afrique (pp. 8-17). Genève: s.e..

\footnotetext{
${ }^{16}$ Querendo precisar o sentido da viagem que quer empreender connosco, no ensaio "para uma redefinição da cultura", Steiner escreve logo no frontispício: "dir-se-ia que estamos, no que se refere a uma teoria da cultura, no mesmo ponto em que a Judite de Bartok, quando pede para abrir a última porta para a noite" (Steiner, 1992, p. 6). Steiner convoca a personagem Judite, do libreto de uma das óperas de Bartok, que tomara como modelo o conto tradicional, No Castelo do Barba Azul. E o seu ensaio sobre a cultura contemporânea, uma cultura de matriz tecnológica, é uma porta aberta sobre "O grande tédio" (título do primeiro capítulo); sobre "Uma temporada no Inferno" (título do segundo capítulo), sobre a "Pós-cultura" (título do terceiro capítulo).
} 
Bastide, R. (1972). Lusotropicology, race, nationalism, class protest and development in Brazil and portuguese Africa. R. H. Chilcote (Ed.), Protest and resistance in Angola and Brazil (pp. 225-240). Berkeley: University of California Press.

Baudrillard, J. (1981). Simulacres et simulation. Paris: Galilée.

Bourdieu, P. (1977). Sur le pouvoir symbolique. Annales, 32(3), 405-411.

Bourdieu, P. (1979). La distinction. Critique sociale du jugement. Paris: Éditions de Minuit.

Bourdieu, P. (1982). Ce que parler veut dire. Paris: Fayard.

Boxer, C. (1963). Race relations in the portuguese colonial empire, 1415-1825. Londres: Oxford University Press.

Brito, R. \& Martins, M. L. (2004). Moçambique e Timor-Leste: onde também se fala o português. In Livro de Atas do III Congresso da Sopcom. Covilhã: Universidade da Beira Interior. Retirado de http://hdl.handle. net/1822/1005

Castelo, C. (1998). "O modo português de estar no mundo". O luso-tropicalismo e a ideologia colonial portuguesa (1933-1961). Porto: Afrontamento.

Chacon, V. (2000). Gilberto Freyre, a globalização e o luso-tropicalismo. In A. Moreira \& J. C. Venâncio (Eds.), O luso-tropicalismo. Uma teoria social em questão (pp. 33-41). Lisboa: Veja.

Chacon, V. (2002). O futuro da lusofonia. Lisboa: Verbo.

Correia, M. L. (2013). Intermitências na cultura visual contemporânea: o postal ilustrado e a imagem recreativa. Tese de doutoramento em Ciências das Comunicação, Universidade do Minho, Braga, Portugal. Retirado de http://hdl.handle.net/1822/29216

Cunha, M. I. (2015). As duas faces da cultura: usos e sentidos de uma noção. J. In Y. Durand \& H. Martins, Olhares e oficios de antropólogos em Espanha e Portugal (pp. 269-291). Braga: CRIA-UMinho. Retirado de http://hdl.handle.net/1822/40115.

Faraco, C. A. (2016). História sociopolítica da língua portuguesa. São Paulo: Parábola.

Faraco, C. A. (2012). Lusofonia: utopia ou quimera? Língua, história e política. In L. Tânia, Z. Carneiro, J. Soledade, A. Almeida \& S. Ribeiro (Eds.), ROSAE. Linguística, História, História das Línguas e Outras Histórias (pp. 31-50). Salvador: EDUFBA.

Fiorin, J. L. (2006). A lusofonia como espaço linguístico. In N. Bastos (Ed.), Língua portuguesa: reflexões lusófonas (pp. 25-48). São Paulo: EDUC.

Foster, H. (2002). Design and crime (and other diatribes). Nova lorque: Verso.

Heidegger, M. (1954/1988). La question de la technique. Essais et conférences. Paris: Gallimard.

Hugon, St. (2010). Circumnavigations. L'imaginaire du voyage dans l'expérience internet. Paris: CNRS Éditions.

Jakobson, R. (1970). Lingüística e Comunicação. São Paulo: Cultrix.

Jenkins, H. (2008). Convergence culture - where old and new media collide? Nova lorque: New York University Press.

Jenkins, H. (2003). Transmedia storytelling. MIT Technology Review. Retirado de https://www. technologyreview.com/s/40176o/transmedia-storytelling/ 
Jost, F. (2011). Novos comportamentos para antigas mídias ou antigos comportamentos para novas mídias? Matrizes, 4(2), 93-109. Retirado de https://www.revistas.usp.br/matrizes/article/download/38294/41119

Jünger, E. (1930/1990). La mobilisation totale. Paris: Gallimard.

Kerckhove, D. de (1997). A pele da cultura - uma investigação sobre a nova realidade electrónica. Lisboa: Relógio D’Água.

Kittler, Fr. (2011). Técnicas artísticas. In M. T Cruz (Ed.), Novos média. Novas práticas (pp. 10-19). Lisboa: Vega.

Lopes, A. J. (2004). A batalha das línguas. Perspectivas sobre Linguística Aplicada em Moçambique. Maputo: IUEM/Fundação Universitária, UEM.

Maffesoli, M. \& Martins, M. L. (2012). Ciberculturas. Revista de Comunicação e Linguagens, 42, 41-52. Retirado de http://hdl.handle.net/1822/23794

Martins, M. L. (1998). A biblioteca de Babel e a árvore do conhecimento. O Escritor, 11/12, 235-240. Retirado de http://hdl.handle.net/1822/30068

Martins, M. L. (2003). O quotidiano e os média. Todas as Letras, 5, 97-105. Retirado de http://hdl.handle. net/1822/1064

Martins, M. L. (2005). Espaço público e vida privada. Revista Filosófica de Coimbra, 27, 157-172. Retirado de http://hdl.handle.net/1822/23799

Martins, M. L. (2007). Nota introdutória. A época e as suas ideias. Comunicação e Sociedade,12, 5-7. DOI: $10.17231 /$ comsoc.12(2007).1092

Martins, M. L. (2009). Ce que peuvent les images. Trajet de l'un au multiple. Les Cahiers Européens de l'Imaginaire, 1, 158-162. Retirado de http://hdl.handle.net/1822/24132

Martins, M. L. (2010). A mobilização infinita numa sociedade de meios sem fins. In C. Álvares \& M. Damásio (Eds.), Teorias e práticas dos media. Situando o local no global (pp. 267-278). Lisboa: Edições Lusófonas. Retirado de http://hdl.handle.net/1822/24250

Martins, M. L. (2011a). Crise no castelo da cultura. Das estrelas para os ecrãs. Coimbra: Grácio Editor. Retirado de http://hdl.handle.net/1822/29167

Martins, M. L. (2011b). Globalization and lusophone world. Implications for citizenship. In M. Pinto \& H. Sousa (Ed.), Communication and citizenship: rethinking crisis and change (pp. 75-84). Coimbra: Grácio Editor. Retirado de http://hdl.handle.net/1822/25344

Martins, M. L. (2011/12). Média digitais - hibridez, interatividade, multimodalidade. Revista de Comunicação $e$ Linguagens, 43-44, 49-6o. Retirado de http://hdl.handle.net/1822/25606

Martins, M. L. (2014). Língua Portuguesa, globalização e lusofonia. In N. M. Bastos (Ed.), Língua portuguesa e lusofonia (pp. 15-33). São Paulo: EDUC - IP-PUC. Retirado de http://hdl.handle.net/1822/29178

Martins, M. L. (2015/2016). Ciências da Comunicação e mundo Lusófono. Anuário Internacional de Comunicação Lusófona, XIII, 11-18. Retirado de http://hdl.handle.net/1822/45164

Martins, M. L. (2015a). Média digitais e lusofonia. In M. L. Martins (Ed.), Lusofonia e interculturalidadepromessa e travessia (pp. 27-56). Famalicão: Húmus. Retirado de http://hdl.handle.net/1822/39698

Martins, M. L. (2015b). Lusofonias - reinvenção de comunidades e combate linguístico-cultural. In M. L. Martins (Ed.), Lusofonia e interculturalidade - promessa e travessia (pp. 7-23). Vila Nova de Famalicão: Húmus. Retirado de http://hdl.handle.net/1822/39703 
Martins, M. L. (2015 c). A liberdade académica e os seus inimigos. Comunicação e Sociedade, 27, 405-420. DOI: $10.17231 /$ comsoc.27(2015).2109

Martins, M. L. (2015 d). Os Estudos Culturais como novas Humanidades. Revista Lusófona de Estudos Culturais / Lusophone Journal of Cultural Studies, 3(1), 341-361. Retirado de http://hdl.handle. net/1822/40655

Martins, M. L. (2017). Comunicação da ciência, acesso aberto do conhecimento e repositórios digitais o futuro das comunidades lusófonas e ibero-americanas de Ciências Sociais e Humanas. In M. L. Martins (Ed.), A internacionalização das comunidades lusófonas e ibero-americanas de Ciências Sociais e Humanas o caso das Ciências da Comunicação (pp. 19-58). Vila Nova de Famalicão: Húmus. Retirado de http://hdl. handle.net/1822/51039

Martins, M. L. (2018a). A lusofonia no contexto das identidades transnacionais e transcontinentais. Letrônica - Revista do Programa de Pós-graduação em Letras da PUCRS, 11(1), 3-11. DOI: $10.15448 / 1984-4301.2018 .1 .30438$

Martins, M. L. (2018b). Communication studies cartography in the lusophone world. Media, Culture Q Society, 4O(3), 458-463. DOI: 10.1177/0163443717752812

Martins, M. L., Cabecinhas, R. \& Macedo, L. (Eds.) (2011). Anuário Internacional de Comunicação Lusófona, Lusofonia e Cultura-Mundo, IX. Braga: Universidade do Minho/Grácio Editor. Retirado de http://hdl. handle.net/1822/36686

Martins, M. L. \& Correia, M. L. (Eds.) (2014). Do post ao postal. Famalicão: Húmus. Retirado de http://hdl. handle.net/1822/35295

Martins, M. L., Oliveira, M. \& Correia, M. L. (2011). Les images numériques s'imaginent l'archaïque: mettre en perspective les cartes postales. Sociétés, 111, 163-177. DOI: 10.3917/soc.111.0163

Morin, E. (1962). L'esprit du temps. Paris: Grasset.

Mungioli, M. C. (2011). A construção de mundos possíveis se tornou um processo coletivo. Entrevista com Carlos Alberto Scolari. Matrizes, 4(2), 127-136. Retirado de www.revistas.usp.br/matrizes/article/ download/38296/41123/

Sahlins, M. (1993). Goodbye to "Tristes Tropiques": ethnography in the context of Modern History. Journal of Modern History, 65, 1-25.

Salmon, Ch. (2007). Storytelling. La machine à fabriquer des histories et à formater les esprits. Paris: La Découverte.

Sloterdijk, P. (2000). La mobilisation infinie. Paris: Christian Bourgois.

Sousa, M. N. (2018). A propagação de histórias através de múltiplos média. Por um modelo conceptual de transmediações, adaptações e outros exercícios derivativos. Tese de doutoramento em Ciências da Comunicação. Universidade do Minho, Braga, Portugal. Retirado de https://repositorium.sdum. uminho.pt/handle/1822/56395

Sousa, M. N., Zagalo, N. \& Martins, M. L. (2012). Eu também posso propagar histórias. A adaptação e as narrativas transmediáticas na era da participação". Comunicação e Sociedade, 22, 167-183. DOI: 10.17231/ comsoc.22(2012).1280

Sousa, M. N., Martins, M. L. \& Zagalo, N. (2016). Transmedia storytelling: the roles and stakes of the different participants in the process of a convergent story, in divergent media and artefacts. In A. Lugmayr \& C. Dal Zotto (Eds.), Media convergence handbook (Vol.2, pp. 117-135). Berlin/Heidelberg: Springer-Verlag. 
Sousa, V. (2017). Da 'portugalidade' à lusofonia. Famalicão: Húmus.

Spivak, G. (1988/1994). Can the subaltern speak? In P. Williams \& L. Chrisman, Colonial and Post-colonial theory. A reader (pp. 66-111). Nova Iorque: Columbia University Press.

Steiner, G. (1971/1992). No castelo do Barba Azul. Notas para a redefinição da cultura. Lisboa: Relógio d’Água.

Todorov, T. (1982). La conquête de l'Amérique. La question de l'autre. Paris: Éditions du Seuil.

Tamen, M. (2018, junho). Ler (entrevista), 149, 20-33.

Tamen, M. (2016, 8 de janeiro). Língua portuguesa. A política da língua. Observador. Retirado de https:// observador.pt/opiniao/politica-da-lingua/

Tamen, M. (2012, 24 de abril). Miguel Tamen. A lusofonia é uma espécie de colonialismo de esquerda. i. Retirado de https://ionline.sapo.pt/467762

Virilio, P. (2001). Entretien avec Paul Virilio. Le Monde de l'Éducation, 294, 135-138.

\section{NotA BIOGRÁFICA}

Moisés de Lemos Martins é Professor de sociologia da cultura e da comunicação na Universidade do Minho (Braga, Portugal), sendo nesta universidade Diretor do Centro de Estudos de Comunicação e Sociedade (CECS), que fundou em 2001. É autor de uma vasta obra académica no campo da epistemologia e sociologia da comunicação.

ORCID: https://orcid.org/oooo-0003-3072-2904

Email: moisesm@ics.uminho.pt; moiseslmartins@gmail.com

Morada: Centro de Estudos de Comunicação e Sociedade, Campus de Gualtar, Universidade do Minho, Braga 4710-057, Portugal

\section{* Submetido: 04.05.2018}

* Aceite: 03.07.2018 